\title{
SOBRE NÚMEROS E NARRATIVAS ESTABELECIDAS: ALGUNS COMENTÁRIOS AO ARTIGO DE CLARA MAFRA
}

Regina Novaes ${ }^{1}$

Clara Mafra inicia seu artigo referindo-se ao movimentado debate sobre as religiōes no Brasil que sucedeu a publicação dos resultados do Censo 2010. Citando vários autores (tais como Carlos Steil, Pierre Sanchis e Renata Menezes) e a si mesma (Mafra, 2012), a autora chama a atenção para as repercussões desses números nas alianças e disputas presentes nos espaços acadêmicos, culturais e políticos deste Brasil (menos) católico.

A partir daí o artigo desenvolve uma série de argumentos que indicam - ao mesmo tempo - a necessidade de maior quantidade e qualidade nos números do Censo e de maiores ambições interpretativas, que incluam características do mundo atual. Mais especificamente, teorias que incorporem "noçôes de incerteza, de imprevisibilidade e a capacidade de lidar com ilhas de ordem em um mar de desordem".

Tais recomendaçôes poderiam desembocar em um embate entre a concretude da empiria e a necessária liberdade para alçar voos teóricos. Buscando compatibilizar esses dois desafios, Clara Mafra nos sugere uma nova metáfora para conciliar números e teorias. A saber: propõe a substituição da metáfora do mapa das religiões - "como uma topografia unidimensional com fronteiras que ocasionalmente se sobrepóem e vazam - por outra, de um holograma, com unidades em constante movimento, com ramificaçôes chegando a ordens inimagináveis de extensões e nós”. Tal metáfora favoreceria tanto a renovação das teorias quanto "operações mais ousadas e flexíveis com os números". Com essa proposta o artigo atiça, simultaneamente, velhas e novas polêmicas no campo dos estudos da religião. Senão, vejamos.

1 Professora da Universidade Federal do Rio de Janeiro - UFRJ e pesquisadora CNPq. E-mail: novaes-regina@uol.com.br

Debates do NER, Porto Alegre, Ano I4, N. 24, P. IO9-II7, JUl./Dez. 2013 


\section{SOBRE A PRODUÇÃO DOS NÚMEROS}

No que diz respeito ao lugar da religião nos Censos do $\mathrm{IBGE}^{2}$, a autora destaca positivamente a continuidade temporal e os sucessivos aperfeiçoamentos metodológicos na coleta de informaçōes. No que diz respeito ao Censo de 2010, destaca, sobretudo, o fato de este ter permitido que o entrevistado indicasse de forma livre o nome da religião ou culto de que faz parte.

Contudo, de seu ponto de vista, a competente "engenharia tecnológica" da coleta do Censo não logra evitar escassez e imprecisão de informações empíricas sobre as religiōes dos brasileiros. Argumentando nessa direção, a autora traz questôes sobre o número de católicos, de "evangélicos não determinados" e de "sem religião" e indaga "até que ponto" esses números representam um suficiente suporte empírico para estudiosos das religiōes no Brasil.

Nesse cenário, sempre reafirmando a importância social, política e cultural dos números do Censo sobre as religiōes no país, a autora sugere dois expedientes que poderiam resultar na melhoria das informações censitárias, a saber: incluir a alternativa "duplo pertencimento" entre as alternativas e incluir uma questão sobre frequência nas atividades religiosas. Dessa forma, diminuiriam dúvidas sobre quantidades e "teríamos alguma indicação da prática religiosa, indo além da autodeclaração da religião de pertencimento".

Não há como discordar dessas observaçōes da autora: tais expedientes certamente colaborariam para nos aproximar mais da vida religiosa dos entrevistados; mas o texto sugere outra questão instigante: até que ponto os estudiosos da religião aproximam (e até subordinam) indevidamente os achados de suas "pesquisas sérias e consistentes", muitas delas qualitativas, aos números que o Censo oferece?

Do meu ponto de vista, essa pergunta provoca outra: números mais consistentes garantiriam melhor aproximação entre resultados de pesquisas quantitativas e qualitativas? Abalariam - por si - as "metanarrativas teoricamente estabelecidas"? Ou a relação entre números e costuras explicativas sempre

2 Como se sabe, este foi o maior e mais recente levantamento populacional realizado no país (20.635.472 pessoas entrevistadas em julho de 2010).

Debates do NER, Porto Alegre, ANo I4, N. 24, P. IO9-II7, JUl./DeZ. 2013 
envolverá escolhas e riscos e, por isso mesmo, sempre guardará um caráter hipotético e reflexivo? Com essa perspectiva, farei os dois comentários a seguir.

\section{EVANGÉLICOS: DE QUANDO OS NÚMEROS ACABAM POR EXIGIR A BUSCA DE OUTROS “INDICADORES”}

Desenvolvendo sua argumentação central, o artigo de Clara Mafra questiona as interpretações sobre a (surpreendente) informação do Censo 2010 de que houve diminuição no crescimento da Igreja Universal do Reino de Deus (calcula-se a perda de 228 mil fiéis), justamente em um contexto em que os evangélicos voltaram a se expandir (em um salto de 26 milhões de seguidores para 42 milhôes), atingindo $22,2 \%$ da população, número esse distribuído em $4 \%$ de evangélicos de missão, 13,3\% de evangélicos pentecostais e $8 \%$ de evangélicos não determinados.

A partir desses números, a autora abre uma interessante discussão, questionando as explicaçóes que têm sido veiculadas sobre essa forte queda da IURD, via de regra indicando uma perda de influência dessa denominação no campo evangélico. Contrapondo-se a esse veredito, a autora coloca em dúvida a excessiva valorização dessa notícia e, por outro lado, relaciona-a com o aumento significativo do "evangélico não determinado" (com 9,2 milhões de respondentes). Cotejando as duas informações, a autora lembra que a IURD não recusa membresia flutuante e usufrui de uma adesão comunitária frouxa, o que poderia levar seus frequentadores esporádicos a se identificarem como "evangélicos não determinados".

Assim, mesmo que não esteja propondo somar a categoria "evangélicos não determinados" ao número dos "membros da IURD", Mafra sugere que a influência dessa denominação pode estar presente entre os evangélicos que não especificam seu vínculo institucional. Nesse cenário, destacam-se três argumentos que revelariam o potencial de influência da IURD.

Vejamos os dois primeiros, ligados às eleiçōes e ao mundo da comunicação. Como indica a autora, a própria igreja se fortalece internamente em momentos eleitorais quando, abertamente, direciona o voto dos frequentadores para candidatos não apenas evangélicos, mas "evangélicos da igreja”. Externa-

Debates do NER, Porto Alegre, ANo I4, N. 24, P. IO9-II7, JUl./Dez. 2013 
mente, evidencia seu poder de influência quando "alimenta redes de internet, eventos transnacionais ocupando avenidas e praças públicas em diferentes cidades, indústria fonográfica de música gospel, consumo de CDs, DVDs, turismo religioso, produção de livros" na lista dos mais vendidos do país.

Esses dois argumentos podem, sem dúvida, ser vistos como "indicadores" úteis para refletir sobre a influência da IURD. Demonstram o poder de influência para dentro e para fora do espaço denominacional. Já o terceiro argumento/indicador remete ao recorte geracional. Clara Mafra - remetendo a evangélicos pentecostais de segunda e terceira geração - observa que os mais jovens estariam buscando experiências religiosas mais plurais e vínculos menos fortes.

Nesse caso, a meu ver, somos conduzidos a um cenário que extrapola a questão da influência exercida pela IURD no campo evangélico. Com efeito, ao falar dos jovens de hoje, podemos visualizar com clareza mudanças mais amplas na sociedade e no movimentado campo religioso brasileiro. Por exemplo, observando a nova geração, fica mais claro o hiato entre os "evangélicos não determinados" e os chamados "católicos não praticantes" ou "católicos nominais". Isso porque, entre os mais jovens, evidenciam-se múltiplos significados de "pertencimento" e de novas combinaçôes para contabilizar "frequência".

Como se sabe, a "cultura católica brasileira" - fruto de uma religião "naturalizada", transmitida de geração a geração - traz consigo a possibilidade de não frequentar cotidianamente a igreja mas, mesmo assim, poder recorrer aos sacramentos e aos rituais de passagem, como batismo, crisma, casamento, missa de sétimo dia etc. (católicos não praticantes). Os “evangélicos”, por sua vez, não se movendo pela mesma lógica sacramental que sedimenta a (re)afirmação de pertencimento institucional católico, destacaram-se pela "frequência" e criaram categorias para definir o afastamento de suas igrejas (desviados, por exemplo).

No que diz respeito às novas geraçôes, se é verdade que o "pertencimento" católico continua ligado aos sacramentos (que ainda não se fazem pela internet), o que parece ter diminuído é o poder do catolicismo de subordinar outros pertencimentos. Isto é, o catolicismo perdeu seu lugar indiscutível de definir as estratégias de apresentação social, o que vem a modificar também a composição dos "católicos não praticantes".

Debates do NER, Porto Alegre, ANo I4, N. 24, P. IO9-II7, JUl./DEZ. 2013 
Por outro lado, como fenômeno recente, os "evangélicos não determinados" também expressam continuidades e mudanças na lógica de "pertencimento evangélico". "Ser evangélico" no Brasil, como afirmei acima, esteve sempre ligado à frequência e à assiduidade às atividades religiosas; mas, para a atual geração juvenil, há outras formas de garantir frequência e assiduidade: pode-se "baixar" cultos e louvores a qualquer hora do dia ou da noite, o que pode vir a modificar também a lógica do pertencimento denominacional.

Isto é, sobretudo ao falar de jovens, entre as muitas vias que podem ser exploradas para a compreensão do número de "evangélicos não determinados" - aos quais tenho chamado de "evangélicos genéricos" -, não me parece possível desconsiderar o mundo virtual. "Indicadores" de frequência e assiduidade devem, portanto, levar em conta as intersecções entre o presencial e o virtual.

Da mesma forma que esta geração reinventa formas de participação política fora (e dentro) dos lugares usuais da política (sindicatos, partidos, movimentos organizados), sua "vida religiosa" e seus "pertencimentos" precisam ser compreendidos na intersecção entre territórios e redes.

\section{OS "SEM RELIGIÃO": DE QUANDO OS NÚMEROS SUGEREM NOVOS SENTIDOS DO "PERTENCIMENTO"}

Clara Mafra também destaca outra informação do último Censo: o crescimento dos "sem religião", cujo número subiu de 7,4\% para 8,0\% (14,5 milhões de respondentes), remetendo ao universo urbano, jovem e masculino.

Ao chamar a atenção para o fato de a maioria dos "sem religião" ter baixa escolaridade, estar na base da pirâmide e ser de cor parda, Clara Mafra - remetendo a trabalhos de Cecília Mariz - menciona a experiência de jovens das periferias que têm sido criados aos cuidados de uma mulher evangélica, aprendendo com suas mães/avós/tias que "ter religião" é sinônimo de "frequentar uma igreja". Como esses jovens não frequentavam uma igreja na época da aplicação do Censo, eles se autodeclararam "sem religião". $\mathrm{Na}$ lógica evangélica: sem frequência = sem religião. Essa hipótese é um bom exemplo de uma produtiva aproximação reflexiva entre investigações quantitativas e qualitativas.

Debates do NER, Porto Alegre, ANo I4, N. 24, P. IO9-II7, JUl./Dez. 2013 
Também respaldada por pesquisas de campo, sugeri em trabalho anterior (Novaes, 2004) que declarar-se "sem religião" na trajetória de vida de jovens brasileiros poderia traduzir: a) um ponto de partida para se descolar das religióes de família; b) um interregno entre distintos pertencimentos; e c) um ponto de chegada (novos tipos de pertencimento) onde se realizam sínteses pessoais combinando elementos de diferentes crenças e tradições religiosas. Assim sendo, trata-se ainda de mapear lógicas e arranjos que resultam em diferentes maneiras de ser "sem religião", sem desembocar obrigatoriamente na lógica do pertencimento/não pertencimento institucional.

Certamente, reconhecer a ampliação de buscas e experimentações religiosas entre jovens não significa dizer que para toda esta geração as instituiçóes religiosas deixaram de ser locus de agregação social, de doação de sentido para a vida e, ainda, espaço motivador de açôes e engajamentos político-sociais. Também não quer dizer que entre esses jovens entrevistados pelo IBGE não exista uma parte que pode ter tido experiências que poderiam ser definidas como de "desconversão", "desfiliação", "desafeição" (ver entrevistas publicadas no IHU On-Line n. 400, 2012).

Porém, essas últimas noções trazem consigo narrativas que generalizam, partindo de supostas experiências de rejeição, de rupturas, de decepções com instituiçôes religiosas e, ainda, de esvaziamento de valores. E, do meu ponto de vista, aí reside o perigo de que "interpretações estabelecidas" resultem em economia de reflexão. A ênfase na "desfiliação" pode ocultar significados da declaração "sem religião" entre jovens.

Enfim, levando em conta as experiências da atual condição juvenil, a clássica ideia de "pertencimento" precisa ser repensada, pois os vínculos se fazem de outros modos e em outros contextos. Considerando que o catolicismo - embora dominante numérica e culturalmente - não tem o mesmo peso relativo, o que define hoje o "duplo pertencimento"? Até que ponto hoje podemos - por adição - falar em "triplo pertencimento"? Que relaçōes de subordinação ou equidade estão em jogo?

Sem dúvidas, a ideia de "duplo pertencimento" muito contribuiu para a compreensão de vivências e das estratégias de apresentação social da religião entre os brasileiros, que se moviam em um campo religioso marcado pela

Debates do NER, Porto Alegre, ANO I4, N. 24, P. IO9-II7, JUl./DEZ. 2013 
hegemonia católica, reconhecida pela cultura e legitimada pelo Estado como evidencia o tradicional calendário dos feriados oficiais.

Naquele contexto, o catolicismo expressava a memória coletiva (religião dos brasileiros) e era a referência mais importante para a conformação da territorialidade. Enquanto religião dominante, o catolicismo subordinou - e não eliminou as possibilidades de convivência desigual - as religiōes de matrizes afro-brasileiras e mediúnicas. Só a expansão do pentecostalismo foi marcada pela ruptura da conversão e pela marca de exclusividade do pertencimento.

No entanto, os jovens de hoje já foram socializados em novo contexto. Diferentemente de seus avós e pais, que viviam em territórios marcados pela presença dominante da Igreja Católica, os jovens de hoje já cresceram em um momento de proliferação de outras igrejas nos espaços onde vivem. Quando um visitante chega e - buscando se localizar - indaga "onde fica a igreja?", eles estão propensos a responder "qual igreja?".

Hoje, imbricando-se nos territórios, existem as redes. O que estou indagando é como e até que ponto os vários tipos de "pertencimentos" também se redefinem e diversificam por meio de novas vinculações (presenciais e virtuais), de convivências e televivências, de combinações entre a realidade contígua e a web-realidade? Nesse contexto, por que não repensar a ideia de "pertencimento" religioso?

Ou seja, cada geração incorpora novos códigos e sentidos de "pertencer" e isso traz diferenças em termos de autodeclaração religiosa, de estratégias de apresentação social e, por conseguinte, de "sofrer preconceitos e discriminações” religiosamente motivados. Para esta geração, as reações negativas frente aos "sem religião" são diferentes (e menos negativas) daquelas experimentadas pelos pentecostais (com suas reiteradas afirmações da crença) e mesmo pelos ateus (situados no outro extremo, com sua negação ativa de crenças).

"Não ter religião" abre tanto um espaço potencial para (re)iniciar adesões institucionais quanto para "interagir" - sem vigilância eclesiástica ou familiar com pessoas de outras religiōes. Estou sugerindo que os "sem religião" podem se mover em espaços de "valorização da diversidade", dos quais pentecostais e ateus se excluem e/ou são excluídos, o que parece indicar que "ser" (ou "estar") "sem religião" pode se apresentar como um estado provisório de suspensão de

Debates do NER, Porto Alegre, ANo I4, N. 24, P. IO9-II7, JUl./Dez. 2013 
pertencimento e, dessa forma, inscreve-se como uma nova posição possível (e aberta) no campo religioso.

\section{NOTA FINAL: DE NOVO, OS SINAIS DOS TEMPOS}

Insistindo na importância do aperfeiçoamento das fontes numéricas sobre as religiōes no Brasil e advogando o apoio de teorias sociais mais abertas e capazes de conviver com alguma incerteza e imprevisibilidade, Clara Mafra buscou expedientes para responder à seguinte pergunta: quais as linhas de força, os ancoradouros e os fluxos presentes no campo das religiōes no Brasil?

Para tanto, sugeriu a metáfora teórica de um holograma que tende a ser formado por muitas versóes de cristianismo com focos de outras religiosidades, que continuam a se constituir mutuamente e no contraste com a nossa versão de secularismo. O caminho pode, sem dúvida, ser promissor, desde que - na apreensão das novas relações entre o catolicismo e as demais escolhas religiosas, cristãs ou não - a metáfora proposta dê conta de entender como a "correlação de forças religiosas" e das determinações do tempo histórico interfere em sua composição e movimentos.

Ou seja, sugiro que, para construir o holograma proposto por Clara Mafra - para além do decréscimo da membresia da Universal, do crescimento da categoria dos "evangélicos não determinados", da tendência de crescimento dos espíritas (de 1,3\% para 2,0\%) e da estabilização das religiōes afro-brasileiras (umbanda e candomblé, com 3\%) -, devemos nos dedicar também a compreender tensões, continuidades e rupturas no interior da própria dominância católica.

Da mesma forma, em uma perspectiva que leva em conta características do mundo atual, pode-se indagar até que ponto as características da Igreja Universal do Reino de Deus, bem destacadas por Clara Mafra, podem explicar tanto seu crescimento em décadas anteriores quanto sua diminuição numérica no Censo de 2010.

A Igreja Universal do Reino de Deus foi precursora da inovação no campo evangélico e, de certa forma, contribuiu para a "capacidade dos evangélicos de criar malhas institucionais sem centros ou com múltiplos centros, com

Debates do NER, Porto Alegre, ANo I4, N. 24, P. IO9-II7, JUl./DEZ. 2013 
ênfase na subjetividade e na capacidade de autogestão". Em outras palavras, a IURD captou e antecipou "sinais dos tempos" e, assim, tanto garantiu sua expansão no Brasil e no mundo quanto - ao mesmo tempo - desenvolveu novos expedientes para que sua "influência" na sociedade não fosse avaliada apenas pelo número indicado pelo Censo.

É em um novo contexto que é preciso entender o que há de novo entre os "sem religião" e entre os "evangélicos não determinados", em sua considerável diversidade de trajetórias e situações. Identificar diferentes trajetórias significa também considerar que, nos dias de hoje, as representaçôes e práticas religiosas não se fazem apenas por dentro dos circuitos institucionais, mas também por fora e à margem. Além disso, tanto dentro quanto fora de circuitos institucionais, tais dinâmicas sempre incluem disputas - e não ausência - de valores.

\section{REFERENNCIAS}

MAFRA, Clara. O percurso que faz o gênero. Religiāo e Sociedade, v. 32, n. 2, p. 124-148, 2012.

NOVAES, Regina. Os jovens "sem religião": ventos secularizantes, "espírito de época" e novos sincretismos. Notas preliminares. Revista Estudos Avançados, v. 18, n. 52, p. 321-330, 2004.

Jornal IHU On-line n. 400, 2012. Disponível em: < http://www.ihuonline. unisinos.br/index.php?option=com_content\&view=article $\&$ id $=4591 \& \mathrm{~s}$ ecao $=400>$. Acesso em: 27 ago. 2012 .

Debates do NER, Porto Alegre, ANo I4, N. 24, P. IO9-II7, JUl./DeZ. 2013 